\title{
Therapy for primary pulmonary hypertension
}

\author{
Dave McCormack MD FRCPC
}

$\mathrm{P}$ ulmonary hypertension is defined as a mean pulmonary arterial pressure of greater than $25 \mathrm{mmHg}$ or a pulmonary vascular resistance of greater than 3 Wood units. According to the 1998 World Health Organization classification (1), pulmonary arterial hypertension may be secondary to known causes such as collagen vascular disease, congenital heart disease, cirrhosis or human immunodeficiency virus infection, or may be idiopathic in etiology, named primary pulmonary hypertension (PPH). Untreated, the latter disease has a very poor prognosis, with a mean survival of less than three years.

Effective therapies for PPH are relatively new to the medical scene; before 1990, there was essentially no treatment for this disease apart from lifelong anticoagulation. In 1992, Dr Stuart Rich and colleagues (2) from the University of Illinois (Chicago, Illinois) identified a subset of patients with $\mathrm{PPH}$ who had a favourable pulmonary vasodilator response (ie, greater than $20 \%$ fall in pulmonary vascular resistance and mean pulmonary artery pressure) in response to acute administration of vasodilators. When these patients were treated with a very high dose of oral calcium channel blockers, they had a greater than $90 \%$ survival rate over five years (2). Although this was very encouraging news for a dismal disease, it was frustrating that only about $20 \%$ of patients with $\mathrm{PPH}$ had this favourable acute (and hence long term) vasodilator response.

Nothing could be done for the remaining $80 \%$ of $\mathrm{PPH}$ patients until the next major breakthough, which came in the mid 1990s. At that time, Barst and collegues (3) reported that treatment with continuous intravenous epoprostenol improved hemodynamic parameters, exercise capacity and survival in patients with $\mathrm{PPH}$. Although this was very encouraging, enthusiasm for this therapy was dampened by the requirement for permanent intravenous access and continous administration of the drug via a portable infusion pump. Despite this, epoprostenol therapy is the only treatment for $\mathrm{PPH}$ that has been demonstrated, in a randomized controlled trial, to lead to improved survival. Further, it has been shown that patients with pulmonary hypertension secondary to the CREST syndrome also have functional improvement when treated with epoprostenol (although no survival benefit has yet been demonstrated in this group of patients) (4). It should be noted that this therapy is not suitable for patients with significant interstitial lung disease secondary to scleroderma.

The next milestone came in 2001, when Channick et al (5) reported that oral therapy with the endothelin receptor antagonist bosentan resulted in improved hemodynamic parameters and increased exercise tolerance in patients with moderately severe pulmonary hypertension due to $\mathrm{PPH}$ or a complication of the CREST syndrome. Endothelin is an endogenously produced vasoconstrictor and vascular smooth muscle mitogen. A large amount of scientific work had already demonstrated an increase in plasma and tissue endothelin levels in patients with pulmonary hypertension. The reason why bosentan therapy for PPH was appealing to physicians (and patients) was because it was an oral therapy and therefore obviated the need for continuous intravenous administration of drug (as in the case of epoprostenol). Nevertheless, unlike epoprostenol, data demonstrating survival benefit for bosentan therapy in patients with pulmonary hypertension are lacking.

Currently, both epoprostenol and bosentan therapy are limited to patients with PPH or pulmonary hypertension secondary to the CREST syndrome (and minimal interstitial lung disease) who are significantly limited in their exercise tolerance (New York Heart Association class III or IV). Both of these therapies are extremely expensive. The current cost of bosentan is approximately $\$ 45,000 /$ year/patient, and the cost of epoprosentol is $\$ 50,000$ to $\$ 150,000 /$ year/patient depending on the dose required. Due to these enormous costs, use of both of these drugs is tightly regulated by the government, and special approval is required for their use.

In summary, when considering therapy in a patient with PPH or pulmonary hypertension secondary to the CREST syndrome (with minimal interstitial lung disease), it is first appropriate to perform an acute vasodilator challenge with a Swan-Ganz catheter in place. If there is an acceptable acute vasodilator response (see above), the patient should be started on long term calcium channel blocker therapy. If there is not a significant acute vasodilator response, the therapeutic choice is between continous intravenous eposprostenol and oral bosentan. Despite the fact that eposprostenol is the only therapy with a demonstrated survival benefit, many specialists begin therapy with bosentan, and closely monitor patients for three to six months for clinical, functional and hemodynamic improvements. If no improvements are noted, therapy is often changed to epoprostenol in patients who are able to tolerate this very arduous therapy. In the absence of a contraindication, all patients with $\mathrm{PPH}$ should be anticoagulated for life. In patients that fail medical therapy, the only remaining option is lung transplantation.

Although therapy for this disease is complicated, expensive and often onerous, we have come a long way in the past 10 to 15 years. Previously, the prognosis was appalling; there are now therapeutic options available that provide these patients with hope.

\footnotetext{
London Health Sciences Centre, London, Ontario

Correspondence: Dr Dave McCormack, London Health Sciences Centre, 375 South Street, London, Ontario N6A 4G5. Telephone 519-667-6767, fax 519-667-6687, e-mail david.mccormack@lhsc.on.ca
} 


\section{REFERENCES}

1. Rich S, ed. Primary Pulmonary Hypertension: Executive Summary from World Symposium. Geneva: World Health Organization, 1998.

2. Rich S, Kaufmann E, Levy PS. The effect of high doses of calcium-channel blockers on survival in primary pulmonary hypertension. N Engl J Med 1992;327:76-81.

3. Barst RJ, Rubin LJ, Long WA, et al. Primary Pulmonary Hypertension Study Group. A comparison of continuous intravenous epoprostenol (prostacyclin) with conventional therapy for primary pulmonary hypertension. N Engl J Med 1996;334:296-302.

4. Badesch DB, Tapson V, McGoon M, et al. Continuous intravenous epoprostenol for pulmonary hypertension due to the scleroderma spectrum of disease. A randomized controlled trial. Ann Intern Med 2000;132:489-98.

5. Channick RN, Simonneau G, Sitbon O, et al. Effects of the dual endothelin-receptor antagonist bosentan in patients with pulmonary hypertension: a randomized placebo controlled study. Lancet 2001;358:1119-23. 


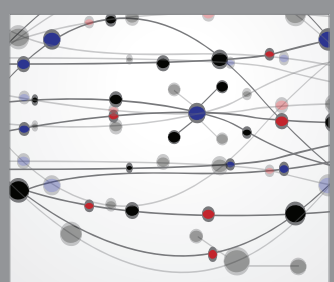

The Scientific World Journal
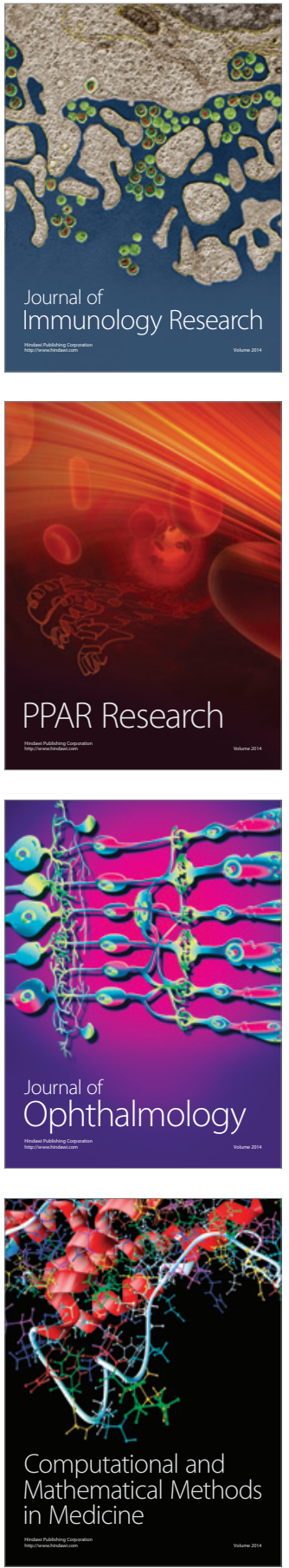

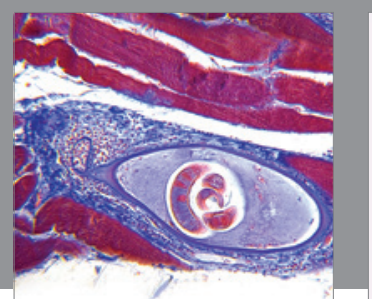

Gastroenterology Research and Practice

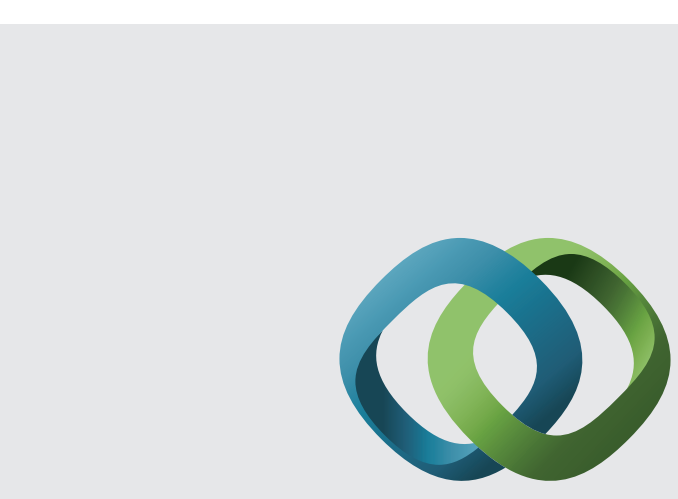

\section{Hindawi}

Submit your manuscripts at

http://www.hindawi.com
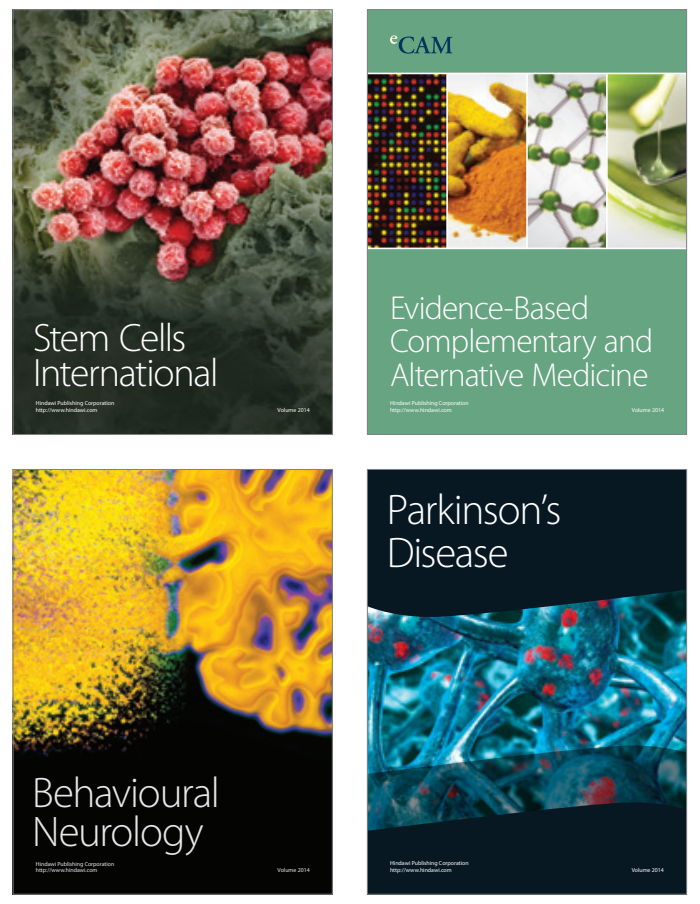
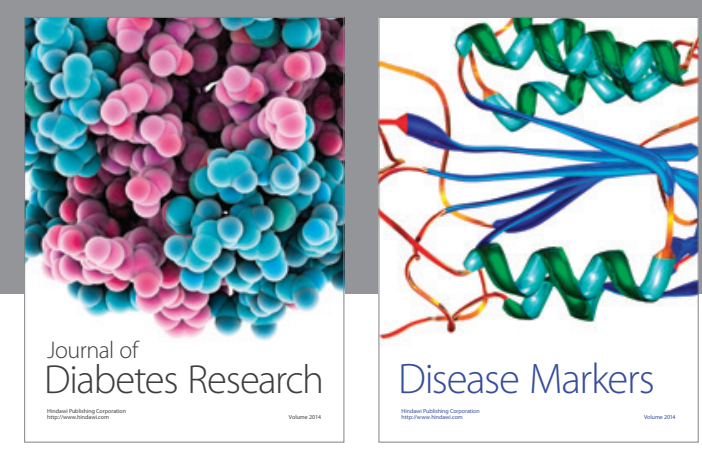

Disease Markers
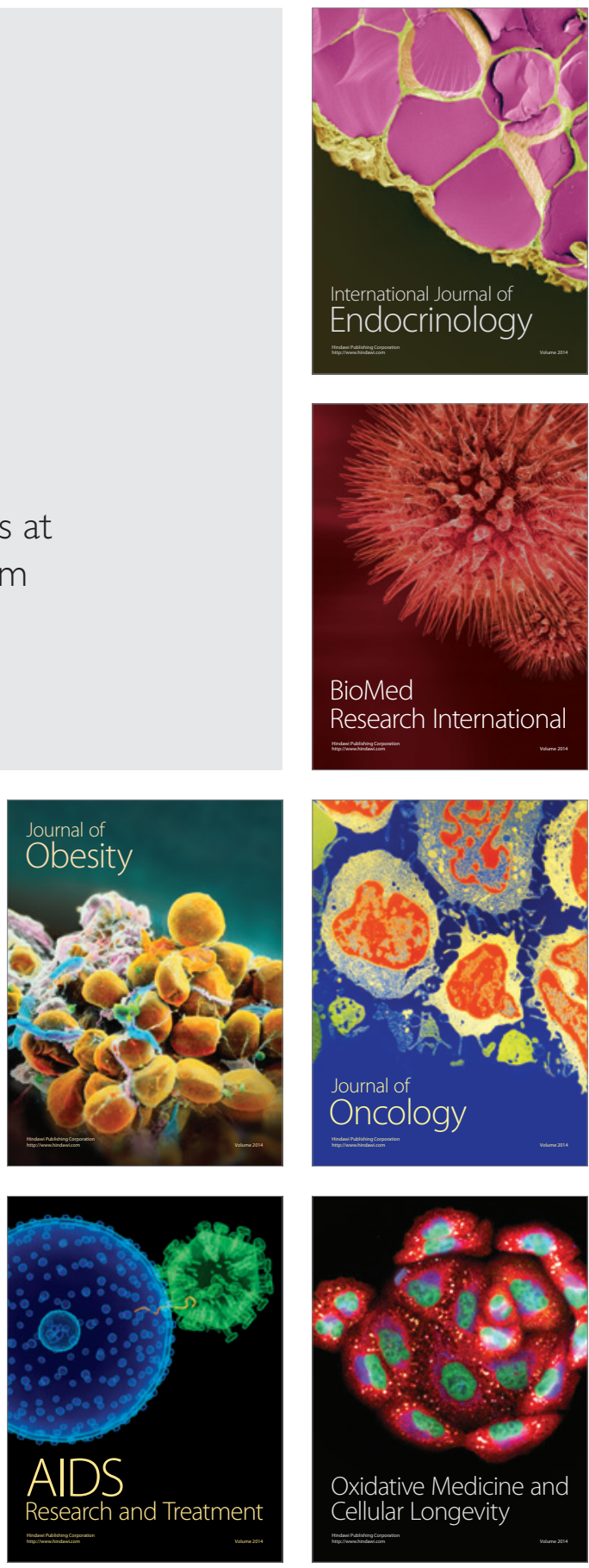